\title{
Screening of Antianxiety Activity of Habenaria Intermedia D. Don Fruits
}

\author{
PAWAN KUMAR ${ }^{* 1}$, REECHA MADAAN ${ }^{2}$ AND SHABIR SIDHU ${ }^{1}$ \\ ${ }^{1}$ IKG Punjab Technical University, Kapurthala - 144601, Punjab, India \\ ${ }^{2}$ Chitkara College of Pharmacy, Chitkara University, Rajpura - 140401, Punjab, India
}

*Email: pawanptukumar@gmail.com

Received: December 27, 2016 | Revised: March 02, 2017 | Accepted: April 01, 2017

Published online: May 05, 2017

The Author(s) 2017. This article is published with open access at www.chitkara.edu. in/publications

\begin{abstract}
Habenaria intermedia D. Don (Vriddhi; Orchidaceae) has been traditionally used in the treatment of nervous disorders, skin disorders and asthma. The available pharmacological reports on $H$. intermedia reveal that the plant has not been screened for antianxiety activity. Thus, it was envisaged to subject $H$. intermedia for screening of antianxiety activity using elevated plus maze model. The crude extracts ( $n$-hexane, chloroform, methanol and water extracts) of plant material were prepared successively in increasing order of polarity. The anxiolytic activity was assessed by comparing number of entries and average time spent by mice treated with test extracts (200 or $400 \mathrm{mg} / \mathrm{kg}$, p.o.) in open arms of EPM with respect to control and standard drug, diazepam (2 mg/kg, p.o.). Significant antianxiety activity was observed in methanol extract with respect to control, whereas $n$-hexane, chloroform and water extracts did not exhibit antianxiety activity. It is further observed that antianxiety activity exhibited by the methanol extract was statistically not equivalent to the standard drug. Based on these observations, it is concluded that the methanol extract of $H$. intermedia exhibits mild anxiolytic activity.
\end{abstract}

Keywords: Antianxiety activity, Habenaria intermedia, Orchidaceae, Vriddhi.

\section{INTRODUCTION}

The demand for anxiolytic agents has been enormously increased to deal with stressful situations in life and modernization borne disorders. Antianxiety medications help in reducing the symptoms of anxiety, panic attacks and extreme fear. For treatment of generalized anxiety disorders benzodiazepines are first choice. Antidepressants are preferred in case of panic disorder or

Journal of Pharmaceutical Technology, Research and Management Volume 5, No. 1, May 2017 pp. 71-75 
Kumar, P. Madaan, $\mathrm{R}$ Sidhu, $\mathrm{S}$

social anxiety disorder (NIMH, 2016). Long term use of benzodiazepines causes depression, addiction and physical dependence (Baldessarini, 2001). Search for effective solutions is needed to treat anxiety disorders. Exploration of plant drugs, based on their traditional uses, seems to be a viable approach.

Habenaria intermedia D. Don (Vriddhi; Orchidaceae) traditionally, used in the treatment of nervous disorders, skin disorders, asthma, cold and fever (Khare, 2007). The plant is mainly distributed in India, Pakistan, Nepal and Bhutan. In India, it is found in Himachal Pradesh, Kashmir, Uttarakhand and Sikkim (Balkrishna et al., 2012). H. intermedia has been reported to contain coumarin - scopoletin and phenol - gallic acid. The plant has been reported to possess hepatoprotective (Goudar et al., 2015), immunomodulatory (Habbu et al., 2012) and antistress activities (Sahu et al., 2013). H. intermedia has not been scientifically validated for its traditional claims of anxiolytic potential. Thus, the present investigations were undertaken with a view to screen antianxiety activity of various extracts of $H$. intermedia.

\section{MATERIALS AND METHODS}

\subsection{Plant material}

The procurement of Habenaria intermedia fruits was made from Himalaya Herbs Store, Madhav Nagar, Saharanpur, UP in September, 2013. Identification of the plant was confirmed by Dr. Avneet Pal Singh, Assistant Professor, Department of Botany, Punjabi University, Patiala, India (Reference No. SPL101/Bot, dated 15-10-2013).

\subsection{Preparation of various extracts}

Two kg coarsely powdered plant material was taken in thimble and placed in a Soxhlet apparatus. It was then extracted exhaustively using $n$-hexane $(10 \mathrm{~L})$ on a water bath maintained at a temperature of $100^{\circ} \mathrm{C}$. The marc was dried, again packed in Soxhlet and extracted exhaustively with chloroform $(10 \mathrm{~L})$ and then with methanol $(10 \mathrm{~L})$ (E Merck, New Delhi, India). The marc of plant was dried and again extracted with distilled water $(10 \mathrm{~L})$ using decoction process for $2 \mathrm{~h}$ on a hot plate maintained at $100^{\circ} \mathrm{C}$. The rotary vacuum evaporator (BUCHI, Switzerland) was used to concentrate crude extracts. All extracts viz., $n$-hexane extract (HE), chloroform extract (CE), methanol extract (ME) and water extract (AQE) were tested to detect various group of phytochemicals by applying general chemical tests (Farnsworth, 1966). 


\subsection{Animals}

Albino mice (Swiss strain; either sex; body weight 20-25 g) were procured from the Panacea Biotech Ltd., Ambala-Chandigarh highway, Lalru, Punjab, India. The animals studies were approved from Institutional Animal Ethics Committee of CT Institute of Pharmacy,Jalandhar(IAEC-CTIPS/2014/V/0029 (PCT - D), dated 15/12/2014). The laboratory pellet diet (Shri Jagdamby Feed Industry, Moga) and water ad libitum were given to mice.

\subsection{Vehicle and standard drug}

The test doses of crude extracts were prepared using vehicle \{Distilled water + Tween 80 (2\%)\}. Diazepam (Triko Pharmaceuticals, Rohtak, Haryana) at the dose of $2 \mathrm{mg} / \mathrm{kg}$, p.o. was used as standard anxiolytic drug.

\subsection{Experimental design}

Experimental protocol, comprises ten groups (I to X), and each group contained 6 mice.

Group I - Mice received vehicle ( $0.25 \mathrm{ml}$, p.o.) served as Control group;

Group II - Mice received diazepam ( $2 \mathrm{mg} / \mathrm{kg}$, p.o.) served as Standard group;

Group III - Mice received HE (200 mg/kg);

Group IV - Mice received HE (400 mg/kg);

Group V - Mice received CE $(200 \mathrm{mg} / \mathrm{kg})$;

Group VI - Mice received CE (400 mg/kg);

Group VII - Mice received ME (200 mg/kg);

Group VIII - Mice received ME (400 mg/kg);

Group IX - Mice received AQE (200 mg/kg);

Group X - Mice received AQE (400 mg/kg);

\subsection{Evaluation of antianxiety activity}

Elevated plus maze model was used to assess antianxiety activity. The parameters assessed were (a) number of open arms entries and (b) time spent (average) in open arms (Prakash et al., 2015).

\subsection{Statistics}

The results of antianxiety activity studies were presented as mean \pm standard deviation (SD). The anxiolytic activity of extracts were compared with diazepam and vehicle using one way ANOVA followed by Student Newman Keul's test (Scheffer, 1980).
Screening of

Antianxiety

Activity of

Habenaria

Intermedia

D. Don Fruits 
Kumar, P. Madaan, R Sidhu, S

\section{RESULTS AND DISCUSSION}

The percentage yields of crude extracts viz., HE, CE, ME and AQE were found to be $0.52,0.48,3.90$ and $2.29 \% \mathrm{w} / \mathrm{w}$ respectively. Qualitative chemical tests showed presence of lipids in HE; alkaloids in CE; coumarins, flavonoids and tannins in ME; and carbohydrates and proteins in AQE. All crude extracts of $H$. intermedia fruits were screened for antianxiety activity using elevated plus maze model (EPM). It is clearly evident from table 1 that ME (200 or $400 \mathrm{mg} / \mathrm{kg}$ ) produced significant antianxiety activity in mice using EPM when compared with control, but the anxiolytic activity exhibited by ME was statistically not similar as shown by the standard drug. HE, CE and AQE could not increase number of entries and time spent by mice in open arms of EPM with respect to control at any tested doses. These observations finally suggest that only ME exhibits mild anxiolytic activity whereas $\mathrm{HE}, \mathrm{CE}$ and WE are devoid of anxiolytic activity.

The EPM model of anxiety was employed for the assessment of antianxiety activity of test drugs because this is easy to handle, less labour oriented, and does not involve any training to the mice (Kaur et al., 2014). In this model the animals are exposed to approach-avoidance conflict (height), which induces anxiety (acrophobia) in animals (Kumar \& Kumar, 2014).

Table 1: Antianxiety activity of various extracts of $H$. intermedia fruits using EPM.

\begin{tabular}{llll}
\hline Treatment & Dose $(\mathbf{m g} / \mathbf{k g})$ & $\begin{array}{l}\text { Number of entries in open } \\
\text { arms (Meann } \pm \text { S.D.) }\end{array}$ & $\begin{array}{l}\text { Time spent in open arms } \\
(\mathbf{s e c}) \text { (Meann } \pm \text { S.D.) }\end{array}$ \\
\hline Control & Vehicle & $2.00 \pm 0.63^{\mathrm{a}}$ & $3.13 \pm 0.28^{\mathrm{a}}$ \\
Diazepam & 2 & $7.67 \pm 1.03^{*}$ & $12.76 \pm 0.47^{*}$ \\
$\mathrm{HE}$ & 200 & $2.33 \pm 0.52^{\mathrm{a}}$ & $2.93 \pm 0.34^{\mathrm{a}}$ \\
& 400 & $2.50 \pm 0.55^{\mathrm{a}}$ & $3.08 \pm 0.23^{\mathrm{a}}$ \\
$\mathrm{CE}$ & 200 & $2.50 \pm 0.84^{\mathrm{a}}$ & $2.81 \pm 0.29^{\mathrm{a}}$ \\
& 400 & $2.67 \pm 0.52^{\mathrm{a}}$ & $2.92 \pm 0.42^{\mathrm{a}}$ \\
$\mathrm{ME}$ & 200 & $5.00 \pm 0.89^{* \mathrm{a}}$ & $8.88 \pm 1.25^{* \mathrm{a}}$ \\
& 400 & $5.50 \pm 1.05^{* \mathrm{a}}$ & $9.00 \pm 0.90^{* \mathrm{a}}$ \\
$\mathrm{WE}$ & 200 & $2.50 \pm 0.84^{\mathrm{a}}$ & $2.86 \pm 0.21^{\mathrm{a}}$ \\
& 400 & $2.67 \pm 0.82^{\mathrm{a}}$ & $2.85 \pm 0.22^{\mathrm{a}}$ \\
\hline
\end{tabular}

$\overline{\mathrm{n}=6 ; * P<0.05 \text { vs Control; }{ }^{\mathrm{a}} P<0.05 \text { vs Diazepam (Standard drug); one way ANOVA followed }}$ by Student Newman Keul's test. 
As coumarins, flavonoids and tannins are major classes of phytoconstituents of bioactive ME, $\mathrm{tt}$ is finally concluded that phenolic compounds may be therapeutically active constituents of $\mathrm{H}$. intermedia.

\section{REFERENCES}

[1] Balkrishna, A., Srivastava, A., Mishra, R.K., Patel, S.P., Vashistha, R.K., Singh, A., Jadon, V. \& Saxena, P. (2012). Astavarga plants - Threatened medicinal herbs of the North-West Himalaya. International Journal of Medicinal and Aromatic Plants, 2(4), 661-676.

[2] Baldessarini, R.J (2001). Drugs and the treatment of psychiatric disorders. In: J.G. Hardman \& L.E. Limbird (Eds.), 10th ed., Goodman and Gilman's The Pharmacological Basis of Therapeutics, New York, The USA, The McGraw-Hill Companies, 399-427.

[3] Farnsworth, N.R.(1966). Biological and chemical screening of plants. Journal of Pharmaceutical Sciences, 55(3), 225-276. https://doi.org/10.1002/jps.2600550302

[4] Goudar, M.A., Jayadevappa, H., Mahadevan, K.M., Shastry, R.A., Habbu, P.V. \& Sayeswara, H.A. (2015). Isolation and characterization of secondary metabolite from Habenaria intermedia D. Don for evaluation of hepatoprotective activity against carbon tetrachloride induced liver damage in albino rats. Asian Journal of Pharmaceutical and Clinical Research, 8(2), 194-198.

[5] Habbu, P.V., Smita, D.M., Mahadevan, K.M., Shastry, R.A. \& Biradar, S.M. (2012). Protective effect of Habenaria intermedia tubers against acute and chronic physical and psychological stress paradigms in rats. Revista Brasileira de Farmacognosia, 22(3), 568-579. https://doi.org/10.1590/S0102-695X2012005000033

[6] Khare, C.P (2007). Indian Medicinal Plants: An Illustrated Dictionary. New York, USA, Spinger Science and Business Media, 301.

[7] Kumar, D. \& Kumar, S. (2014). Evaluation of antianxiety activity of Calotropis gigantea roots. Journal of Fundamental Pharmaceutical Research, 2, 30-37.

[8] Kaur, K., Kumar, D. \& Kumar S. (2014). Screening of neuropharmacological activities of Calotropis gigantea roots. Journal of Pharmaceutical, Chemical and Biological Sciences, 2(3), 186-196.

[9] NIMH, 2016. National Institute of Mental Health. http://www.nimh.nih.gov/health/topics/anxiety-disorders/index.shtml.

[10] Prakash, O., Kumar, D. \& Kumar, S. (2015). Screening of methanol extract and ethyl acetate fraction of Abies webbiana Lindl. for neuropharmacological activities. Indian Journal of Pharmaceutical Sciences, 77(5), 536-541. https://doi.org/10.4103/0250-474X.169039

[11] Sahu, M.S., Sahu, R.A. \& Verma, A. (2013). Immunomodulatory activity of alcoholic extract of Habenaria intermedia in mice. International Journal of Pharmacy and Pharmaceutical Sciences, 5(Suppl. 3), 406-409.

[12] Scheffer, W.C (1980). Statistics for the Biological Sciences. Philippines, Addison-Wesley Publishing Company, 121-141.
Screening of

Antianxiety

Activity of

Habenaria

Intermedia

D. Don Fruits

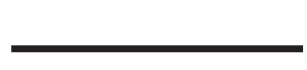

